\title{
Note-taking in Persian-English Consecutive Interpreting: Considering Iranian Translation Teachers' and Students' Opinions
}

\author{
Rasoul Marani \\ Department of English, Islamic Azad University, Isfahan (Khorasgan) Branch, Isfahan, Iran \\ Hossein Heidari Tabrizi \\ Department of English, Faculty of Foreign Languages, Islamic Azad University, Isfahan (Khorasgan) Branch, Isfahan, \\ Iran
}

\begin{abstract}
Note-taking is one of the essential skills which is used to facilitate the process of consecutive interpreting and the different aspects of the cited skill has been investigated in the history of interpreting. But despite of this significance, very little related research could be found about note-taking in Persian-English consecutive interpreting. Due to this paucity, the present study explored and examined the translation teachers' and students' opinions in this respect in order to identify the weaknesses of teaching and utilizing note-taking during the process of consecutive interpreting particularly in Iranian academic contexts. For the purpose of this research, four interpreting teachers from different Iranian universities, besides $\mathbf{1 0}$ male and female undergraduate translation students of quoted academic context who had passed interpreting courses, were selected meticulously and by means of phone interview, the required data were collected. The results of this investigation clearly indicate that, as well as teaching interpreting courses by the non-qualified teachers more often than not, the used syllabuses for interpreting courses do not cover all aspects of the issue and should be redesigned according to the students' future needs in the role of the professional interpreters. Additionally, while almost all general concepts, techniques and strategies are totally unfamiliar to translation students, they entirely acknowledge the necessity of learning much more about note-taking.
\end{abstract}

Index Terms — essential skills, interpreting syllabuses, Iranian academic context, teaching note-taking, utilizing note-taking

\section{INTRODUCTION}

With the advent of different nations and languages, translation as a kind of mediator had narrow the existing gap between people and made them closer from different aspects specially in cultural and commercial relations. Although it seems that the oral translation was initially used, due to the lack of relevant documents, in translation studies the written translation has a longer history. However, after 1950s interpreting as the new concept of the oral translation was defined by some scholars like Hermann (1956/2002) and Vermeer (1992). Subsequently, because of the increasing attention to the field of interpreting, several classifications of this concept have been introduced in accordance with the time, place, and type of the used translation which the two most famous and applied types named simultaneous and consecutive interpreting.

Regardless of general similarities of the two named famous types of interpreting, they are significantly different when performing. For example, while the vocal pause plays a key role in consecutive interpreting, there is no pause during the simultaneous type, that means the listening and speaking processes occur at the same time. Moreover, unlike the other type, consecutive interpreting is mostly used when the exchange of statements between gatherings is a twoway communication. Furthermore, necessity of using special tools such as electronic devices and booths in simultaneous interpreting can be mentioned as the significant differences. On the other hand in consecutive, the interpreters' performance depend on some essential skills including listening comprehension, language proficiency, and more importantly note-taking skill, which should be taught in interpreting courses.

According to Chen (2016), at first in the prescriptive approach of note-taking literature the authors mostly introduced note taking systems and principles and all the works in this stance tried to explain how notes should be taken based on the writer's personal experiences whether as a professional interpreter or as an interpreter trainer also some times in both responsibilities. Evidently, the first note taking system was presented by Rozan in 1956. Then after, adapting his rules, other experts such as Allioni (1989), Becker (1972), Gillies (2005), Kirchhoff (1979) and Matyssek (1989) established their own systems usually built on the Rozan's system.

Applying practical note taking principles, language experts faced with two challenges. The first one is the possibility of teaching note taking systems and principles to students and the second one is how to teach them methodically. This situation led to beginning of a shift from prescriptive to descriptive approach. Meanwhile, the theory of individuality 
was developed and some authors rejected the systematic teaching of note taking because they believed that note-taking is an individual activity and should not be thought. However, Researchers such as Ilg and Lambert (1996) Seleskovitch and Lederer (1995), who did not accept the individuality theory, conducted some major studies targeted three different group: post graduated interpreting students, undergraduate language students, and community interpreters. Although because of apparent differences between students teachers had to use various objectives and training materials. Finally, a similar result was obtained from research that is in the process of interpreting taking note could draw attention away from other activities. Thus one of the emphasized recommendations to the students is not to taking notes at the initial steps of learning in order to focus on other exercises such as speech analysis, memory training, and summarizing.

Afterwards, considering the fact that quality is a central issue of the interpretation teaching, researchers concentrated on the relationship between note-taking and interpreting quality in their investigation and subsequently used student interpreters as participants. In 2007, Dam tested her previous hypotheses proposed in 2005 by her and some other scholars about features of efficiency and non-efficiency of notes. She analyzed notes taken by 5 professional interpreters during the process of interpreting between Spanish to Danish and proved two hypotheses: "the more notes, the better the target text and vice versa" and "the more abbreviations/the fewer full words, the better the target text and vice versa" (p. 194). Before Dam (2007), Her (2001) conducted a study analyzing the notes taken by undergraduate students interpreting between Chinese and English. The results showed direct relationship between the quality of notes and the quality of interpreting. She also added that all qualified notes did not necessarily result in a qualified interpretation. After that, other scholars such as Dai and Xu (2007), and Wang and Zhou (2010) could not affirm Dam's hypothesis and found no effective relationship between the quality of notes and interpreting. Similarly, Cardoen (2013) rejected Dam's two aforesaid hypotheses and claimed that fewer notes, more full words and fewer abbreviations lead to fluent chunks. She arranged her study by using students as participants and setting the language pair of Spanish and Dutch.

Since the last few decades, according to the basic characteristic of interpreting which is a cognitively demanding task, the third approach to interpreting studies named cognitive load. Although most of studies related to this subject such as Seeber (2011, 2013), Tommola and Hyona (1990) investigate cognitive load in simultaneous interpreting, few research can be found on cognitive load in consecutive interpreting. Seeber's (2013, p. 19) definition of cognitive load is "the quantity of capacity the performance of a cognitive task takes up in a naturally capacity- limited system." Reviewing the relevant analysis of note-taking show that the main issue is keeping the efficacy of notes while decreasing the cognitive load of taking notes. A number of experts like Paas and Merrienboer (1994) and Paas, Tabbers, Tuovinen, and Van Gerven (2003) worked specifically on the cognitive load theory and introduced two aspects of this theory: The first one indicates the factors influencing cognitive load named causal dimension and the second one demonstrates the factors affecting by cognitive load called assessment dimension including mental load, mental effort and performance. Chen (2016) worked on the assessment factors and related measures in detail.

In light of the foregoing review, it seems that examining and analyzing the trainers' and tranees' opinions about the interpreting courses especially in the respect of note-taking is one of the forgotten topics in this field. In other words, there is a noticeable lack of research investigating the interpreting teachers' and students' views, ideas, and their positive or negative attitudes towards note-taking systems, principles also related teaching methods. So, considering the learners' contribution to the learning process as the processor, performer, and initiator also the teachers' role as the catalyst, consultant, and content determiner in quoted process (Richards \& Rodgers, 2001), this study attempted to explore trainers' and trainees' opinions about note-taking exclusively in the Persian-English consecutive interpreting in order to identify the weaknesses of teaching and utilizing cited skill particularly in Iranian academic contexts.

\section{METHOD}

Each study could be categorized according to its time and aim. Based on the aim of research, there are three kinds of investigations named fundamental, applied, and developmental. In this regard, Saldanha and O'Brien (2014) classified research into two main types: basic versus applied research. Correspondingly, Chesterman and Williams (2002) considered research as conceptual and empirical ones (quoted in Mousavi 2015). Therefore, this study is called an empirical one, because data collection has been done by means of phone interviews from real practices. Additionally, time is a considerable criterion of research grouping by which studies are divided into historical, survey, and experimental research. Regarding the fact that this research involved selecting a sample of respondents from a population and administering the phone interview, this is a survey one. Furthermore, since the main question in this paper is 'What are the translation teachers' and students' opinions about note-taking in Persian-English consecutive interpreting" it is labeled as an interpretative study (Ary, Jacobs, Razavieh, \& Sorensen, 2010).

\section{A. Participants}

Having taken into account all the indispensable details, two different groups of people were invited to participate in this study: interpreting teachers and translation students. The characteristics and the selecting procedure for each of which are particularly explained in below.

1) Interpreting Teachers. To form the first group of participants, the researcher faced some difficulties. For example, because of the transport and cost problems, the number of available teachers was restricted. Nevertheless, a 
list of those teachers was prepared from which four volunteers from different universities consisted of Shahrekord University, Islamic Azad University of Isfahan (Khorasgan), and Sobh-E-Sadegh Institute of Higher Education accepted to give a one-session phone interview. To stablish this sample (henceforth referred to as 'Group A') which is done through the stratified random sampling, the important factor was their involvement in teaching interpreting and another characteristics such as sex, age, being faculty members of English department of universities and the years of experience in teaching were disregarded.

2) Translation Students. To complete the participants' arranging process, 10 translation students (henceforth referred to as 'Group B') were selected through the cluster sampling method because the target population was widely dispersed; subsequently preparing a list of members of that population was not possible. So, five male and five female translation students were randomly chosen from eight universities, namely Kharazmi University in Tehran; Islamic Azad University of Isfahan (Khorasgan) and of Shahreza, Payame Noor University of Isfahan (Main Branch, ShahinShar, Najaf Abad, Golpayegan, and Dolat Abad Branch) which every academic year accept translation students and offer the interpretation courses in their programs. Except sex, other characteristics of the students such as age and average grade that had no effect on the result were not considered. Table 1 shows the demographic characteristics of participants including their type, sex, number, age, and so on:

TABLE 1

DEMOGRAPHIC CHARACTERISTICS OF PARTICIPANTS

\begin{tabular}{|c|c|c|c|c|c|c|c|c|c|}
\hline \multirow{2}{*}{$\begin{array}{l}\text { Types of } \\
\text { Participants }\end{array}$} & \multirow{2}{*}{ No. } & \multirow{2}{*}{$\begin{array}{l}\text { Age } \\
\text { Range }\end{array}$} & \multicolumn{2}{|l|}{ Sex } & \multicolumn{3}{|c|}{ Educational Background } & \multirow{2}{*}{ Nationality } & \multirow{2}{*}{$\begin{array}{l}\text { Native } \\
\text { language }\end{array}$} \\
\hline & & & Male & Female & Ph.D. & M.A. & B.A. & & \\
\hline $\begin{array}{l}\text { Interpreting } \\
\text { Teachers }\end{array}$ & 4 & $30-53$ & 3 & 1 & 2 & 2 & - & Iranian & Persian \\
\hline $\begin{array}{l}\text { Translation } \\
\text { Students }\end{array}$ & 10 & $25-36$ & 5 & 5 & - & - & 10 & Iranian & Persian \\
\hline
\end{tabular}

\section{B. Instruments}

According to Lincoln and Guba (1985), in qualitative study there is a primary instrument which is researcher themselves. That is, in order to collect data comprehensively in this type of research that deals with human experiences, there is a need of mutable instrument to capture all complexity of situation. In addition to this natural instrument, to understand the participants' opinions' and beliefs about not-taking in their own words, the phone interview was chosen as the main research instrument with the following particulars and specifications: a semi-structured interview including a set of questions in an open-ended format in which the attention span was limited so that the important topic made clear for interviewees (Arey et al., 2010). What is noteworthy is that because of the responders' scattering, conducting a face to face interview was time-consuming and impossible in some cases. So ignoring the parties' inability to use noneverbal channel of communications, the researcher decided to replace phone interview with the earlier mentioned type for it has some advantages like being cheaper and quicker than the other types, availability of respondents from a dispersed population, deletion of traveling hardship, reduction of interviewer's effects, and so forth (see Cohen, Manion \& Morrison, 2007).

\section{Procedures}

Since two different groups of participants had been determined for interview, two different types of questions was needed. Moreover, no similar and related interview had been conducted by other researcher previously. Therefore, considering the topic of this paper, the researcher himself prepared two series of questions covering all important aspect of the issue. Then after, fourteen phone interview session were heled for the members of group A and B one by one as the interviewee by the researcher as the interviewer. Each session lasted approximately 15 minutes which was completely in Persian to ensure that the participants could share their ideas precisely. All the interviews were taperecorded to transcribe and to analyze the given answers.

According to Mackey and Gass (2005), in a qualitative research before analyzing the raw data, the collected information should be organized to a manageable and easily understandable form. So, the transcribed recorded interviews were classified and their fundamental and important parts were highlighted. Subsequently, regarding the research topic, the data were codified by identifying their implicit facts and themes to extract a logical conclusion from the main points. Simply put, in qualitative research, one of the common ways of codification is examining the data for emergent patterns and themes while concerning anything related to the research goal. Lastly, through the mentioned schemas and settings, the data were narrated by the investigator.

\section{RESULTS}

As it mentioned previously, responders of the interview were two different groups answered via dissimilar but related questions that each of which will be reported as the following. 
Without regard to the general initial question which was about the teachers' years of experience in training interpreting, the following questions were addressed.

1) Interview Question Two. Are you familiar with methods and general principles of note-taking in consecutive interpreting? All the teachers indicated that tailored to the needs of the course, they are familiar with this issue. But further explanation given exposed that their knowledge do not cover all aspects of the topic technically.

2) Interview Question Three. Do you believe that teaching note-taking is a need for interpreting courses? Why? Responds to this question showed a total consensus on the necessity of teaching note-taking. One of the teachers explained that due to lake of language proficiency among translation students, who do not have enough experience to handle a consecutive interpreting, teaching some essential skills such as note-taking could be helpful for them in order to have a better performance.

3) Interview Question Four. Do you teach note-taking in your interpreting courses? Depending on the number of sessions devoted to the courses, all teachers allocated almost 2 or 3 sessions in the semester to introduce note-taking concept and its related issues. Therefore, because of this limitation covering at least one of the appropriate resources of this topic is impossible and just a brief sketch of this skill would be given to students. As a result, no practice could be done and note-taking will remain as a theoretical issue in those courses.

4) Interview Question Five. Do you believe that the existing methods and principles of note-taking are applicable in Persian-English consecutive interpreting or they should be localized for that situation? Except on member, others confirmed the idea proposed by Group $\mathrm{A}$ in the same question and they added that nature of each language is an effective elements during the process of note-taking and using principles complied with the language spoken in consecutive interpreting could reduce the amount of attention needed for writing down the source language words on the one hand, and it could accelerate the production of target language words on the another hand.

5) Interview Question Six. Do you believe that teaching note-taking would affect the performance of students as an interpreter in the future or not? The received answers indicated that besides other supporting techniques and strategies of interpreting, note-taking by reducing short memory usage, causes the better allocation of interpreters' focuses on the other important parts of interpreting. Consequently, the more concentration the interpreters have, the strong performance they would produce.

\section{B. Phone Interview with Group B (Translation Students)}

As the opening question the interviewer asked about the university in which they passed the B.A. program also the number of credits regarding to the interpreting courses. Then other specific questions were posed as below respectively.

1) Interview Question Three. Are you familiar with methods and general principles of note-taking in consecutive interpreting? All participants responded that they do not know anything about note-taking particularly and they are not familiar with basic concepts of interpreting generally. Not surprisingly, some members of this group did not distinguish different modes of interpreting from each other at all.

2) Interview Question Four. Were the interpreting techniques be taught in your interpreting courses? As all interviews declared, they usually passed 2 or 3 interpreting courses in their educational program at B.A. level but they had never seen the relevant syllabus of note-taking in each course. Rarely, in some cases all their written practices were focused on the transcription of some audio or video files which is totally irrelevant exercise.

3) Interview Question Five. Do you believe that teaching note-taking is a need for interpreting courses? Why? Having not a clear picture of the note-taking, all students agreed that since this is an inseparable part of consecutive interpreting, training this issue is seen as a vital need for translation students.

4) Interview Question Six. Do you believe that learning note-taking would affect your performance as an interpreter in the future or not? Although none of the interviewees had experience of consecutive interpreting in a real situation, they all stated that one of the biggest challenges which interpreters face with is the human short-memory limitation that can be solved via learning note-taking skills.

\section{DISCUSSION}

Based on the findings of the first group's interview, teaching note-taking is not considered as a main part of interpreting courses' syllabus among most Iranian universities by reason of several matters. First and foremost reason is that, a significant number of those courses are taught by teachers who are mostly not graduated in translation studies and they usually don't have enough experiences in interpreting too, whereupon they are not familiar with the common teaching methods of note-taking neither academically nor experimentally. Further, time limitation can be mentioned as the second reason. Actually, covering all interpreting skills completely during one or two semester is surely impossible. Additionally, the other major reason is the students' lack of language proficiency which results in curriculum changes by teachers. It means that teachers usually are forced to teach initial abilities such as speaking and listening comprehension instead of technical skills like note-taking and memory enhancement.

However, there is a small number of teachers who completely and methodically teach note-taking in their interpreting courses. To facilitate learning, they usually start the course by native language practices (Persian language) and let the students to gained initial experiences of note-taking without regard to other language barriers. Then, general rules and principles are taught but students are still free to apply them in detail or not. It means that they are not obliged to follow 
all rules absolutely while taking notes and personal methods are applicable besides. Sometimes, sharing note-taking experiences could be more beneficial rather than to teach a specific rule. But it should be bear in mind that experience does not eliminate the need of learning.

Not surprisingly, results related to the second group interviewees are compatible with Dabaghi, Moinzadeh, and Mobasheri (2015) and show that a high percentage of translation students not only are unacquainted with general concepts of interpreting but also are not introduced to techniques and strategies used in consecutive interpreting such as note-taking, regardless of the type of university at which they had studied. That is why they could not be of the opinion that whether not taking has significant effect on their performances as the interpreter or not. But all of them largely concur with the fact that note-taking skill should be taught in interpreting courses because according to the Giles's Effort Model, this skill is an integral part of consecutive interpreting process and it can obviate the need for more time and memory to remember the speeches. More emphatically, for students who want to do interpreting purposefully and professionally in the future, learning essential skills specifically note-taking is not only a need but also a must.

As a translation student, the researcher own experiences reveled the unpleasant fact that ignoring the real objectives of interpreting courses, teachers usually replace the syllabus of apparently similar but basically different courses with the primary designed curriculum to achieve those objectives. Simply put, instead of teaching interpreting, they deliberately or inadvertently teach topics like laboratory courses which are actually for improving students' listeningspeaking skills in their B-language (mostly English) or audio-visual translation courses which are about movie translation. Sadly enough, it has resulted in the students' incompetence.

\section{CONCLUSION}

Referring the previous discussion, in this paper the interpreting teachers' and translation students' opinions about note-taking in Persian-English consecutive interpreting was investigated. So based on the interpreted results, the conclusion is twofold. First, in spite of the fact that almost all general concepts, techniques and strategies are totally unfamiliar to translation students, they entirely acknowledge the necessity of learning much more about note-taking. Second, as well as teaching interpreting courses by the non-qualified teachers more often than not, the used syllabuses for interpreting courses do not cover all aspects of the issue and should be redesigned according to the students' future needs in the role of the professional interpreters. Broadly speaking, as the other researchers like Heidari Tabrizi (2008) and Mousavi (2015) argued, translation studies program at Iranian academic context needs to be revisited in the respect of most curriculums. Also the researcher emphases that translation profession should be more complied with the relevant academic issues.

Emphatically, each research study is confronted with some limitations which can affect the obtained results that should be considered and specified to avoid in future research. The most considerable limitation refers to time shortage. Conducting totally fourteen phone interviews with participants was excessively time consuming task which added to the time spent for transcribing tape-recorded speeches. Furthermore, the scarcity of Iranian related studies as well as inaccessibility to some useful foreign interpreting source books imposed extra limitations which run into several difficulties. Finding and replacing the alternative sources not only took so long time but also was impossible sometimes.

Despite of the quoted limitations, this study opens up some interesting questions for further research. For example, the similar study can be conducted considering other two language pairs instead of Persian and English. That is, researcher can redesign this study based on two language pairs except the ones examined here. The findings obtained from those research may result in different conclusions or may support this investigation. The other suggestion which seems to be more logical is that other essential skills for consecutive interpreting such as short-term memory enhancement should be considered by investigator and its effect on the interpreters' performance could be examined. Moreover, this subject can be studied from extra linguistic aspects like sociolinguistic or psycholinguistic features.

As the ending point, it should be noted that there is a distinguishable difference between two concepts note-taking and note-making. Although the former is widely used in the vast majority of literature on the consecutive interpreting, it seems that the latter is more appropriate term to express what exactly is done by an interpreter while jotting the words. Simply put, note-taking means to write down all the words of the speaker completely, but note making means to write down words needed for reproducing speeches in the other languages.

\section{REFERENCES}

[1] Allioni, S. (1989). Towards a grammar of consecutive interpretation. The Theoretical and Practical Aspects of Teaching Conference Interpretation. Udine: Campanotto.

[2] Ary, D., Jacobs, L. Ch., Razavieh, A. \& Sorensen, Ch. (2010). Introduction to research in education. (8th ed.). Belmont: Wadsworth.

[3] Becker, W. (1972). Notizentechnik. Germersheim, Germany: BBK.

[4] Chen, S. (2016). Note taking in consecutive interpreting: A review with special focus on Chinese and English literature. The Journal of Specialised Translation, Issue26, 151-170. Retrieved from http://www.jostrans.org/ (accessed 12/06/2017).

[5] Chesterman, A. \& Williams, J. (2002). The map: A beginner's guide to doing research in translation studies. Manchester: St. Jerome Publishing.

[6] Cardoen, H. (ed.) (2013). The Effect of Note taking on Target-Text Fluency. Leuven, Belgium: CETRA. 
[7] Cohen, L. Manion, L. \& Morrison, K. (2007). Research methods in education (5th ed.). London: Routledge. Retrieved from http://www.jostrans.org/ (accessed 12/06/2017).

[8] Dabaghi, A., Moinzadeh, A. \& Mobasheri, M. (2015). Accreditation of interpreter training courses curriculum in bachelors of English translation in Iranian universities. International Journal of Applied Linguistics and English Literature, Vol 4, No 6, 1-7

[9] Dai, W. \& Xu, H. (2007). An empirical study of the features of interpreters' notes in Chinese-English consecutive interpreting: The examples of professionally trained and unprofessional interpreters. Foreign Language Teaching and Research, 39(2), 136144.

[10] Dam, H.V. (2007). What makes interpreters' notes efficient?: Features of (non-)efficiency in interpreter's notes for consecutive. Doubts and Directions in Translation Studies: Selected contributions from the EST Congress, Lisbon 2004, (Vol. 72), $183-197$.

[11] Gillies, A. (2005). Note taking for consecutive interpreting: A short course. Manchester. St. Jerome. Retrieved from http://books.google.com/book (accessed 10/06/2017).

[12] Her, H. (2001). Notetaking in basic interpretation class: An initial investigation. Studies of Translation and Interpretation, 6 , 53-77.

[13] Heidari, H. (2008). Towards developing a framework for the evaluation of Iranian undergraduate students' academic translation (Doctoral thesis, Shiraz University, Iran).

[14] Hermann, A. (1956/2002). Interpreting in antiquity (R. Morris, Trans). In F. Pochhacker \& M. Shlesinger (Eds.), The interpreting studies reader. London/New York: Routledge, 15-22

[15] Ilg, G. \& Lambert, S. (1996). Teaching consecutive interpreting. Interpreting 1(1), 69-99.

[16] Kirchhoff, H. (1979). Die notationssprache als hilfsmittel des konferenzdolmetschers im konsekutivvorgang. Sprachtheorie und Sprachpraxis. Tübingen: Gunter Narr.

[17] Lincoln, Y. S. \& Guba, E. (1985). Naturalistic Inquiry. Beverly Hills: Sage.

[18] Mackay, A. \& Gass, S. M. (2005). Second language research: Methodology and design. Mahwah, N.J.: Lawrence Erlbaum Associates.

[19] Matyssek, H. (1989). Handbuch der notizentechnik für dolmetscher. Heidelberg: Julius Groos

[20] Mousavi, M.S. (2015). Interpreter training specific techniques: A didactic approach. (Doctoral thesis, Allameh Tabataba'i University, Iran).

[21] Paas, F. \& Merriënboer V. (1994). Instructional control of cognitive load in the training of complex cognitive tasks. Educational Psychology Review 6(4). 351-371

[22] Paas, F., Tuovinen, J., Tabbers, A., \& Gerven, V. (2003). Cognitive load measurement as a means to advance cognitive load theory. Educational Psychologist 38(1), 63-71.

[23] Richards, J. C. \& Rodgers, Th. S. (2014). Approaches and methods in language teaching. (3th ed.). England: Cambridge University Press.

[24] Saldanha, G. \& O'Brien, Sh. (2014). Research methodologies in translation studies. London: Routledge.

[25] Seeber, K. G. (2011). Cognitive load in simultaneous interpreting: Existing theories - new models. Interpreting 13(2), 176-204.

[26] Seeber, K. G. (2013). Cognitive load in simultaneous interpreting: Measures and methods. Target 25(1), 18-32.

[27] Seleskovitch, D. \& Lederer, M. (1989/1995). A systematic approach to teaching interpretation. (J. Harmer, Trans.). Silver Spring, MD: Registry of Interpreters for the Deaf

[28] Tommola, J. \& Hyona, J. (1990). Mental load in listening, speech shadowing and simultaneous interpreting: A pupillometric study. Foreign Language Comprehension and Production. Turku: AfinLA.

[29] Vermeer, H. J. (1992). Skizzen zu einer Geschicte der Translation. Frankfurt: Verlag fur interkulterelle Kommunication.

[30] Wang, W. D. Z. \& Wang, L. (2010). An empirical study of note taking characteristics and output quality in interpreting. Foreign Language World 4, 9-18.

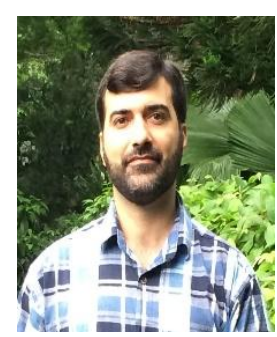

Rasoul Marani (Iran, 1983) is currently a master's student in English Translation Studies at the Islamic Azad University, Isfahan (Khorasgan) Branch (IAUKB), Isfahan, Iran. He completed his bachelor's degree in English Translation at Payame-noor University at Isfahan, in 2010.

His previous study titled 'Professional Interpreters' Notes in Persian-English Consecutive Interpreting: On the Choice of Form and Language" was published by RELP (Research in English language pedagogy), Volume 5, Issue 2, Summer and Autumn 2017, Page 133-146. Translation studies especially interpreting are his research interests.

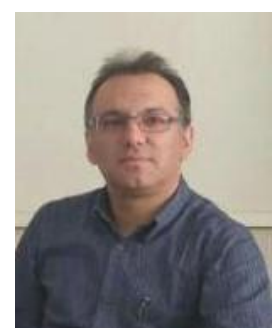

Hossein Heidari Tabrizi (Iran, 1969) is an assistant professor of TEFL at the English Department of Islamic Azad University, Isfahan (Khorasgan) Branch (IAUKB), Isfahan, Iran. His research interests include Testing, Translation studies, Discourse Analysis, and Sociolinguistics. 